\title{
Instability of integrated viral DNA in mouse cells transformed by simian virus 40
}

(tsA58 transformants/simian virus 40 integration/autonomous viral DNA/transformed cell evolution)

\author{
John B. Hiscott, David Murphy, and Vittorio Defendi \\ Department of Pathology, New York University Medical Center, New York, New York 10016 \\ Communicated by Igor Tamm, December 1, 1980
}

\begin{abstract}
The state and organization of simian virus 40 (SV40) DNA in tsA mutant-transformed mouse clones were examined early after agar selection in an attempt to elucidate the mechanisms that actively generate the diverse integration patterns found in transformed cells. Although recently selected as a cloned population from agar, A21 cells displayed extremely heterogeneous SV40 DNA patterns when analyzed by agarose gel electrophoresis and Southern blot hybridization. Reselection of clones in agar from $\mathrm{A21}$ at $33^{\circ} \mathrm{C}$ or $39.5^{\circ} \mathrm{C}$ and DNA analysis by hybridization demonstrated (i) simplification of the number of integration sites in the new clones; (ii) new sites of integrated SV40 DNA in high molecular weight cell DNA fragments generated by digestion with restriction endonuclease $B g l$ II; (iii) relatedness between clones with respect to integrated viral sequence arrangement; and (iv) persistence of free viral DNA forms. The majority of free viral DNA appeared to be full length, nondefective SV40 DNA, although a subpopulation of defective viral molecules was also detected. No detectable free SV40 DNA could be observed in A21 clonal derivatives isolated by growth in agar at $39.5^{\circ} \mathrm{C}$, indicating that the persistence of free viral forms was regulated by the $A$ gene. These results suggest that the heterogeneity in viral sequences in the A21 cells was generated within a cloned population from which new clones can be derived with different transformed phenotypes and integration patterns.
\end{abstract}

Virus-induced carcinogenesis requires both the introduction and the expression of new viral genetic information in transformed cells $(1,2)$. Established cell lines transformed by simian virus 40 (SV40) contain viral sequences covalently associated with cellular DNA (3-7) and synthesize two early virus specific polypeptides $(8,9)$ that play critical roles in the establishment of the transformed state (10-13).

The integration of SV40 DNA sequences into the host genome is an example of illegitimate recombination, which lacks site specificity with respect to both the viral and the cellular genome (7). Analysis of the state and organization of integrated SV40 DNA has revealed that viral sequences are often associated with cellular DNA in complex tandem arrangements that appear to be remarkably stable $(1,2,7,14)$. Only rarely has loss of integrated viral genomes from transformed cells been reported; in these cases, the deletion was detected after application of a negative selection procedure, such as fluorodeoxyuridine treatment, and often involved loss of the SV40 containing chromosome (15).

The stability of integrated SV40 DNA even in "nonpermissive" cells may be somewhat misleading, however, because integration patterns are usually examined long after the initial selection for transformants. The complexity of SV40 integration patterns nonetheless indicates, a posteriori, that the generation of these integration structures involves extensive recombina-

The publication costs of this article were defrayed in part by page charge payment. This article must therefore be hereby marked "advertisement" in accordance with 18 U. S. C. $\$ 1734$ solely to indicate this fact. tion or replication events or both early after infection. In an attempt to elucidate the mechanisms that actively generate the diverse integration patterns found in transformed cells, we have examined in detail the stability of integrated SV40 DNA early after transformation in an agar-selected ts $A$ mutant-transformed mouse line.

\section{MATERIALS AND METHODS}

Cells and Virus. The isolation and characterization of cell lines used in this study have been described in detail elsewhere $(16,17)$. Briefly, confluent secondary cultures of mouse embryo fibroblasts were infected with 50 plaque-forming units per cell of SV40 tsA58 virus, isolated and kindly provided by P. Tegtmeyer (18). Infected mouse cell cultures were maintained at $33^{\circ} \mathrm{C}$ and $40^{\circ} \mathrm{C}$. Colonies were selected from agar at $33^{\circ} \mathrm{C} 3$ weeks later and grown up on plastic. New clones derived from A21 by growth in agar at $33^{\circ} \mathrm{C}$ or $40^{\circ} \mathrm{C}$ were picked from agar at 21 and 14 days, respectively.

High Molecular Weight Cell DNA Preparation. Cellular DNA was extracted from transformed clones by a previously described procedure $(16,19)$.

Isolation of Free Viral Molecules from High Molecular Weight DNA. Undigested high molecular weight A21 DNA $(500 \mu \mathrm{g})$ was electrophoresed through $0.7 \%$ agarose at $40 \mathrm{~V}$ for $15 \mathrm{hr}$. With endonuclease EcoRI-digested $\lambda$ and SV40 DNA $(1 \mu \mathrm{g})$ and undigested SV40 form I and form II DNAs used as markers, the area of the preparative gel corresponding to these viral forms was cut out and placed in dialysis tubing containing $3 \mathrm{ml}$ of electrophoresis buffer. The DNA was electroeluted from the gel by applying a constant $100-\mathrm{mA}$ current and concentrated from the electrophoresis buffer by ethanol precipitation of the solution in the dialysis bag. The precipitate was resuspended in $1 \mathrm{ml}$ of $10 \mathrm{mM}$ Tris $\cdot \mathrm{HCl}(\mathrm{pH} 7.4) / 0.1 \mathrm{mM}$ EDTA (pH 7.4) and extensively dialyzed against the same buffer.

Analysis of Restriction Endonuclease-Generated Fragments. High molecular weight DNA or preparatively isolated DNA was digested to completion by using the appropriate restriction enzymes and buffers (New England BioLabs) as described in detail elsewhere (16). Restriction endonuclease products were resolved by electrophoresis through $0.7 \%$ or $1 \%$ agarose gels in electrophoresis buffer (20) at $40 \mathrm{~V}$ for $15 \mathrm{hr}$. Restriction patterns of $\lambda$ DNA were measured for molecular weight reference markers.

Blot Hybridization. DNA was transferred from the agarose gel to a nitrocellulose sheet (Millipore HAWP) and hybridized to a radioactive probe by a modification of the Southern method (21), as described (16).

Abbreviations: SV40, simian virus 40; kb, kilobase(s). 


\section{RESULTS}

State of SV40 DNA in tsA Mutant-Transformed Mouse Cells Early After Selection. After infection of mouse embryo cells at $33^{\circ} \mathrm{C}$ for $96 \mathrm{hr}$ with 50 plaque-forming units of SV40 tsA58 per cell, viral transformants were selected by anchorage-independent growth in agar for 21 days. The growth characteristics of a representative temperature-sensitive clone, A21, have been described elsewhere $(16,17)$. Within 20 generations after agar selection of A21 cells, high molecular weight cell DNA was extracted and analyzed by digestion with restriction endonucleases possessing different specificities for SV40 DNA to determine the state and organization of virus specific DNA sequences.

The results of this analysis, which are illustrated in Fig. 1, produced two unexpected observations. First, many cellular DNA fragments that hybridized with differing intensities to ${ }^{32} \mathrm{P}$ labeled SV40 probe were generated by restriction endonuclease digestion with different enzymes, in addition to the generation of DNA species that would be expected from digestion of nondefective viral DNA (Fig. 2). For example, digestion of A21 high molecular weight DNA with restriction enzymes that cleave SV40 DNA at one point on the viral genome, such as $B g l$ I, EcoRI, and BamHI (Fig. 1B, lanes 1-3, respectively) generated linear 5.2-kilobase (kb) SV40 DNA, while cleavage with enzymes cutting SV40 DNA more than once [Hpa I, Pvu II, and Pst I (Fig. 1B, lanes 5-7, respectively] produced the expected

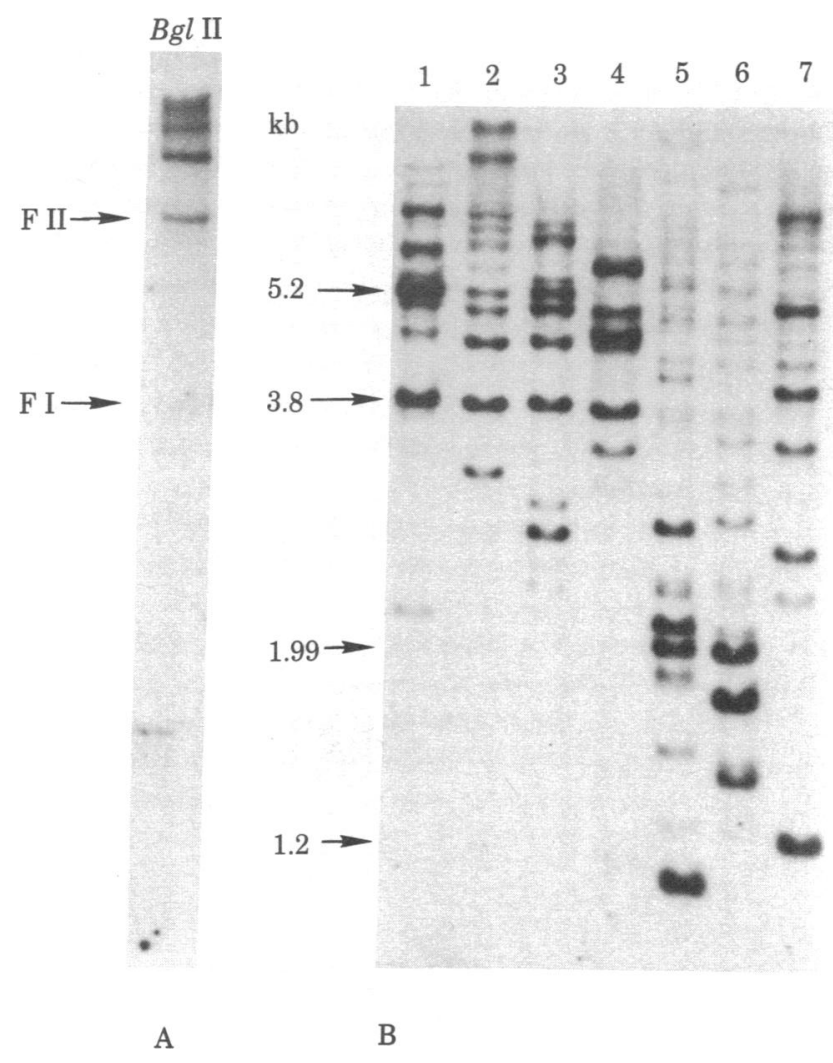

FIG. 1. Detection of SV40-specific sequences in high molecular weight A21 DNA. High molecular weight DNA was extracted from A21 cells, digested with various restriction endonucleases in appropriate buffers (New England BioLabs), and analyzed by electrophoresis through $0.7 \%(A)$ or $1.0 \%(B)$ agarose. DNA fragments were transferred to nitrocellulose and hybridized with SV40 $\left[{ }^{32}\right.$ P DNA. $(A)$ Digestion products of $B g l \mathrm{II}$. (B) Digestion products of: lane 1, $B g l \mathrm{I}$; lane 2, EcoRI; lane 3, Bam HI; lane 4, Taq I; lane 5, Hpa I; lane 6, Pvu II; lane 7, Pst I. F I and F II indicate positions of SV40 DNA form I (covalently closed supercoiled circular DNA) and form II (relaxed circular DNA).

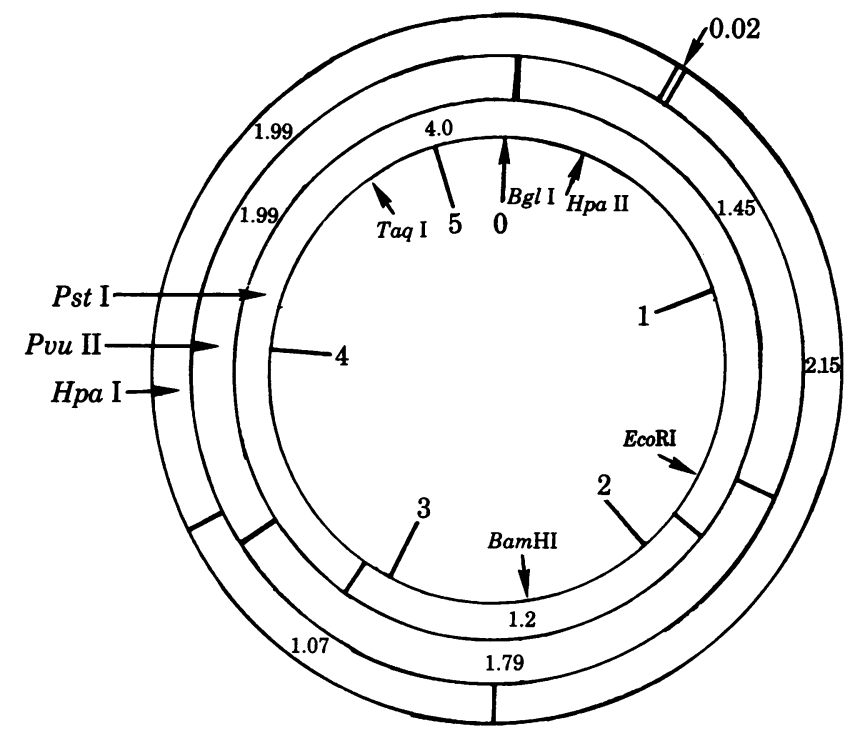

FIG. 2. Restriction map of SV40 DNA. The figure is divided into $1-\mathrm{kb}$ intervals (inner circle), with the origin of replication ( $B g l$ I site) as the zero point. The sites of cleavage of restriction endonucleases cutting SV40 once (Bgl II, Hpa II, EcoRI, BamHI, Taq I) are shown on the inner circle. Relevant multiple-cut enzymes (Pst I, Pvu II, Hpa I) produce the size fragments shown on the three outer circles. The early region of the viral genome runs counterclockwise from approximately the $B g l$ I site to the BamHI site.

subgenomic viral fragments (Fig. 2). These results indicafed that A21 cells, although recently selected as a cloned population from agar, displayed extremely complex SV40 DNA patterns when analyzed by blot hybridization; in fact, the blot patterns appeared to be characteristic of a heterogeneous and uncloned population (Fig. 1).

The second unexpected finding was the presence of SV40containing molecules that comigrated with SV40 DNA forms I, II, and III. The initial indication of the existence of free viral forms in nonpermissive transformed mouse cells came by treating isolated high molecular weight DNA with restriction enzymes lacking specificity for the SV40 genome (Fig. 3). After treatment of A2l DNA with the "no-cut" enzymes Sma I (Fig. 3, lane 1) or Tha 1 (Fig. 3, lane 2) followed by analysis of the fragments of blot hybridization, three faint rapidly migrating bands were produced that comigrated with SV40 DNA markers; identical bands were also obtained with undigested DNA (Fig. 3, lane 3).

To determine if viral DNA existed in both the free and integrated states, A21 DNA was digested with the Bgl II enzyme, which lacks specificity for SV40 DNA but cleaves mouse cellular DNA far more extensively than Sma I or Tha I does (unpublished observation). As illustrated by Fig. 1A, blot hybridization of $B g l$ II-digested A21 DNA produced three distinct high molecular weight, SV40 DNA-containing bands at 12,14 , and 24 $\mathrm{kb}$. In addition, two SV40 DNA bands that comigrated with SV40 forms I and II (Fig. 3, lanes 4 and 5) were seen clearly, although in this blot the high molecular weight bands did not transfer efficiently.

From these observations two main conclusions may be reached: (i) SV40 DNA sequences are integrated into mouse cellular DNA sequences with a wide molecular weight range; (ii) early after clonal selection of transformants, viral DNA species existed in A21 cells both in a free state as covalently closed circular molecules and in the integrated state, covalently linked to mouse cellular DNA. 


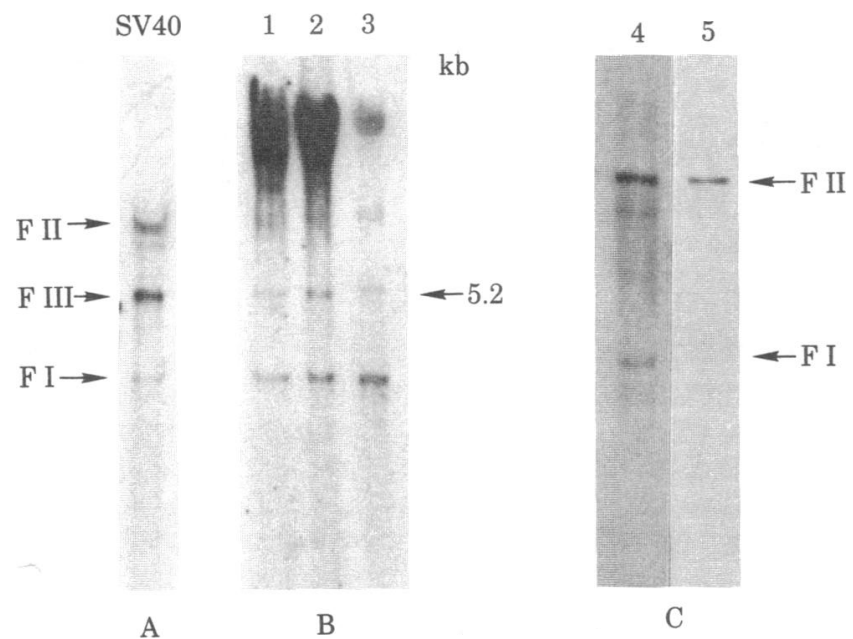

Fig. 3. Detection of free SV40 DNA after digestion of A21 DNA with restriction enzymes lacking specificity for SV40. Digested DNA samples $(10 \mu \mathrm{g})$ were electrophoresed in $0.7 \%$ agarose, transferred to nitrocellulose, and hybridized to SV40 probe. (A) SV40 DNA, forms I, II, and III, Sma I digestion. (B) Lane 1, A21 DNA, Sma I; lane 2, A21 DNA, Tha I; lane 3, A21 DNA, undigested. (C) Lane 4, A21 DNA, Bgl II; lane 5, SV40 DNA, Bgl II.

Analysis of A21 Clonal Derivatives. Two possibilities existed to explain the marked heterogeneity of viral DNA sequences in A2l cells: $(i)$ during the initial selection of transformants from agar, more than one clone or surviving, non-colony-forming cells were inadvertently picked up, or (ii) the viral sequence heterogeneity was being generated within the clonal population at this early stage after transformation. If the original A2l clones had evolved a complex subpopulation containing many different SV40 integration patterns due to a labile interaction of viral
DNA with the host genome, analysis of new clones from the "mixed" population should demonstrate both simplification of the viral DNA arrangement in the new clones and a relatedness among clones with respect to viral sequence arrangement. On the other hand, if in the original isolation of A2l several in dependent cells had been selected, the new clones should also have a simpler arrangement but would not display any relatedness with respect to SV40 sequence arrangement.

To distinguish between these possibilities, A21 cells were recloned in agar at both $33^{\circ} \mathrm{C}$ and $39.5^{\circ} \mathrm{C}$, colonies were selected, and high molecular weight DNA extracted from these cells was analyzed for SV40 sequences. It should be noted that although it is possible to isolate temperature-independent $t s A$ mutant-transformed mouse cells from a temperature-sensitive parental line $(16,17)$ A21 cells form colonies in soft agar with a 100 -fold higher efficiency at $33^{\circ} \mathrm{C}$ than at $39.5^{\circ} \mathrm{C}(16,17)$. In all, 12 new clonal derivatives of A21, 6 isolated at each temperature, were analyzed for SV40-specific sequences. Representative blot analyses from four of these clones after DNA digestion with $B g l$ II, Bgl I, and Pst I are illustrated in Fig. 4. Digestion of A21 clonal derivatives with the Bgl II enzyme, which lacks specificity for SV40 DNA but cleaves mouse cell DNA extensively (Fig. 4A), demonstrated several distinct high molecular weight cellular DNA fragments that contained SV40 sequences. A21/1 (33) and A21/2 (33) clones (Fig. 4A, lanes 1 and 2) contained viral sequences in several cell DNA fragments ranging from 9 to $30 \mathrm{~kb}$ and, in addition, displayed two bands corresponding to SV40 forms I and II. The analysis of clones A21/1 (39.5) and A21/2 (39.5) produced simpler but seemingly unrelated SV40 DNA-containing cell DNA fragments (Fig. 4A, lanes 3 and 4); significantly, A21 clones selected at $39.5^{\circ} \mathrm{C}$ lacked any detectable bands corresponding to free viral DNA. From this analysis with $B g l \mathrm{II}$, the integration patterns appeared totally unrelated, particularly in those lines isolated at $39.5^{\circ} \mathrm{C}$,

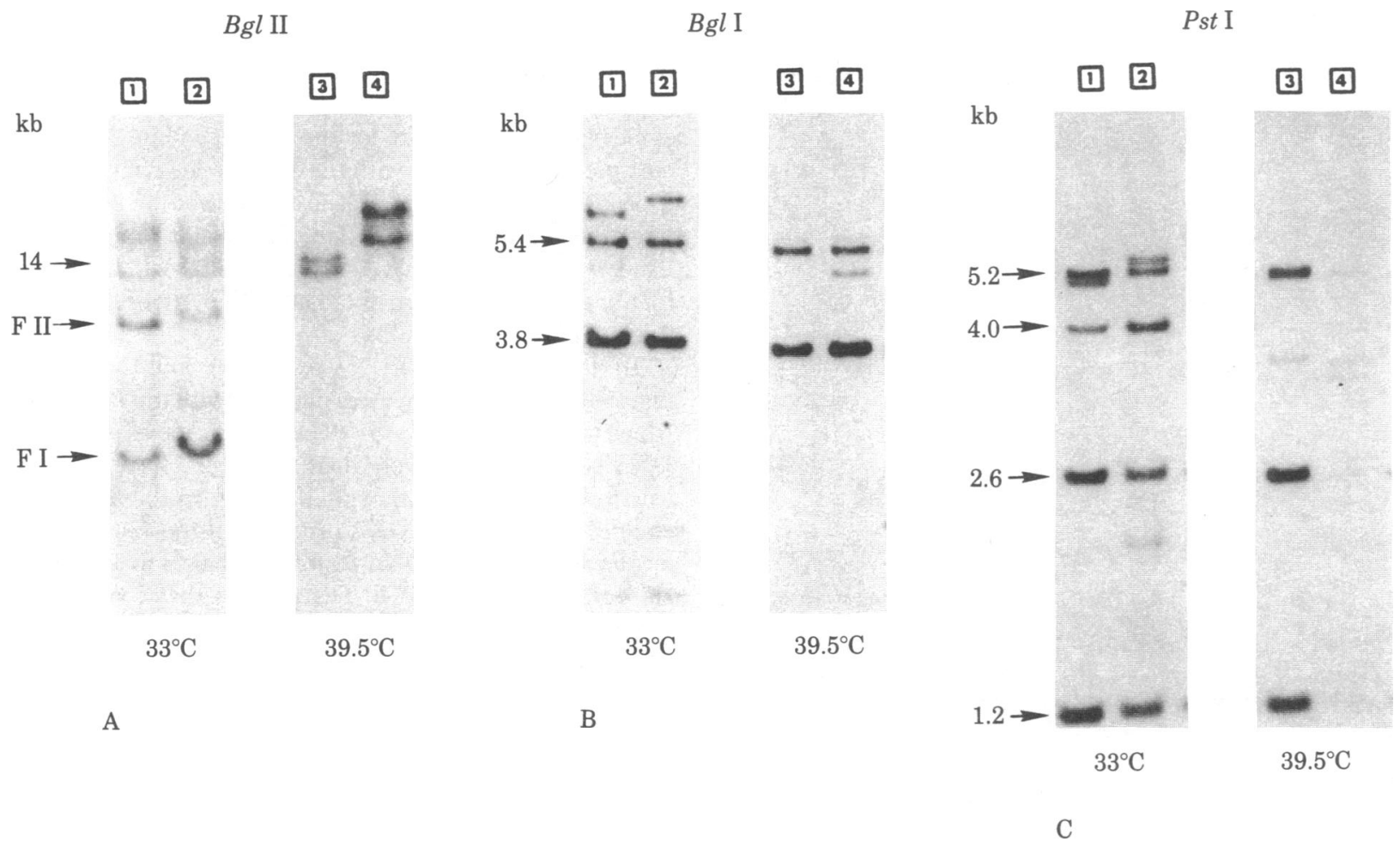

Fig. 4. Detection of SV40 DNA sequences in high molecular weight DNA of clonal derivatives of A21. DNA (10 $\mu$ g) from the reselected A21 clones was digested with $B g l \mathrm{II}(A), B g l \mathrm{I}(B)$, or $P s t \mathrm{I}(C)$ enzymes, electrophoresed in $0.7 \%(A)$ or $1.0 \%$ agarose $(B$ and $C)$, transferred to nitrocellulose, and hybridized with SV40 probe. In all panels: lane 1, A21/1 (33); lane 2, A21/2 (33); lane 3, A21/1 (39.5); lane 4, A21/2 (39.5). 
and indicated that the initial selection of multiple clones was indeed a possibility.

Analysis of A21 clones with Bgl I and Pst I, however, demonstrated clearly the clonal derivation of all the newly selected lines (Fig. $4 B$ and $C$ ). Blot hybridization of DNA from A21 clones after digestion with $B g l$ I enzyme, which cleaves SV40 sequences at a point close to the origin of DNA replication (Fig. 2 ), produced two common SV40 DNA-containing fragments in all clones of 5.4 and $3.8 \mathrm{~kb}$ (Fig. $4 B$ ). Detailed analysis of these molecules (16) has shown that the 3.8-kb fragment represents a tandemly integrated defective viral monomer lacking a 1.4-kb DNA segment in the late region of the viral genome between the $B g l \mathrm{I}$ and $E c o R I$ sites, whereas the 5.4-kb fragments contain both viral and cellular sequences. Analysis of these clones with $B g l$ I produced, in addition to the two major SV40 DNA fragments, several weakly hybridizing bands [for example, A21/2 (33) in Fig. 4B, lane 2] that represented a subset of the sequences observed in the original A21 clone (Fig. 1B, lane 1). Similarly, digestion of A21 clonal derivative DNA with Pst I, which cleaves SV40 DNA to yield fragments of $4.01 \mathrm{~kb}$ and 1.22 $\mathrm{kb}$, produced three common SV40-containing DNA fragments (Fig. $4 C$ ) of $5.2,2.6$, and $1.2 \mathrm{~kb}$. The 2.6 -kb fragment was generated from the $3.8-\mathrm{kb}$ defective molecule, while the $5.2-\mathrm{kb}$ molecule represents a host cell-substituted molecule (16). The relative simplicity of these $B g l \mathrm{I}$ and Pst I digests, despite the heterogeneity of the number of sites indicated by $B g l$ II digests, was indicative not only of a similarity between clones but also of a relatedness between the various integration sites.

It thus seems apparent that from an original A21 clone containing at least three $B g l$ II-defined integration sites at 12,14 , and $24 \mathrm{~kb}$, a complex subpopulation of cells has evolved containing many different integration patterns, due to an inherent integration instability of the transforming viral DNA. When new A21 subclones are selected and analyzed for SV40 sequences within Bgl II restriction fragments, viral DNA-containing cellular fragments usually represent a subset of the fragments seen in the heterogeneous population (Fig. 4A, lane 3), although bands also become distinct that were not detectable in the original A2l population.

All A21 clones reselected at $33^{\circ} \mathrm{C}$ contained an additional Pst I fragment of $4.0 \mathrm{~kb}$, which would be expected from digestion of a full-length nondefective viral molecule; this particular fragment was not detectable in clonal derivatives of A21 isolated at $39.5^{\circ} \mathrm{C}$. These results, taken together with the observation that no detectable free SV40 forms could be demonstrated in clones derived by growth in agar at $39.5^{\circ} \mathrm{C}$, suggested that selection at $39.5^{\circ} \mathrm{C}$ resulted in loss of free DNA species from these clones. Furthermore, the persistence of these free forms was $A$ gene-regulated, because inhibition of functional $A$ gene expression produced a loss of autonomous SV40 DNA; the dependence of the free viral DNA on the viral $A$ gene also ruled out the possibility that these forms were simply nonreplicating input viral DNA.

To test directly the dependence of the free viral DNA in A21 cells on a functional $A$ gene, the population of transformed cells was shifted to $39.5^{\circ} \mathrm{C}$ and passaged at that temperature; with time (approximately 2 weeks) detectable free viral genomes disappeared (data not shown). These results are analogous to the observations obtained with polyoma virus ts= $a$-transformed rat cells (22).

Analysis of Free Viral DNA in A21 Cells. In order to characterize the structure of the free SV40 DNA, viral molecules were separated from high molecular weight cell DNA as outlined in detail in Materials and Methods and analyzed by restriction endonuclease digestion. As illustrated in Fig. 5, lanes
1 and 2, the majority of the SV40 DNA from A21 cells migrated as either form II or form III DNA. Control experiments using form I DNA from SV40 virions and preparatively isolated by electrophoresis and electroelution also produced predominantly form II and form III DNA (data not shown), indicating either that the extraction procedure resulted in breakage of supercoiled SV40 DNA from A21 cells or that form I DNA transferred to nitrocellulose with less efficiency than form II or form III DNA.

Analysis of autonomous viral DNA forms with enzymes cleaving SV40 once (EcoRI, Bgl I, Hpa II, and BamHI; Fig. 5, lanes 3-6, respectively) produced linear 5.2-kb molecules that comigrated with form III marker. These enzymes, with the exception of EcoRI, also generated minor bands in addition to the expected full-length linear molecule; for example, $B g l$ I (Fig. 5 , lane 4) produced two light bands of 3.4 and $1.8 \mathrm{~kb}$, whereas Hpa II (Fig. 5, lane 5) generated SV40 fragments of 3.8 and 1.4 $\mathrm{kb}$. These defective species may represent a subpopulation of viral molecules that contain a reiteration and inversion of the sequences around the viral origin of replication and thus are cleaved twice by $B g l \mathrm{I}$ and $\mathrm{Hpa} \mathrm{II}$; it is also possible that base changes or incorporation of cellular DNA containing the Bgl I or $\mathrm{Hpa}$ II sites could produce the observed results. Analysis of free forms with multi-cut enzymes Pvu II, Hpa I, and Pst I (Fig. 5 , lanes 7-9, respectively) indicated that the majority of these molecules were full-length, nondefective SV40 DNA species. Determination of the basic arrangement of integrated SV40 DNA in these cells (16) demonstrated that these molecules were not derived from the integrated state by excision. In conclusion, the analysis of free viral DNA forms demonstrated that autonomous SV40 persisted in transformed mouse cells early after selection under the control of the SV40 A gene function.

\section{DISCUSSION}

In this report, extensive postintegration lability of the viral genome has been described in the mouse embryo fibroblast clone
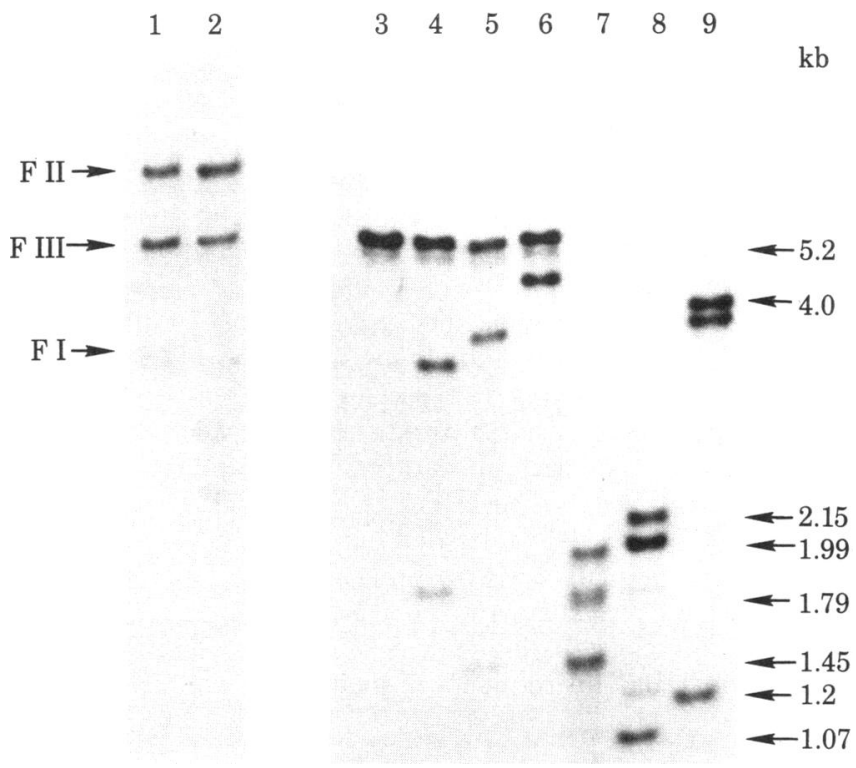

FIg. 5. Analysis of isolated free SV40 DNA from A21 cells. Free viral DNA was isolated from A21 high molecular weight DNA $(500 \mu \mathrm{g})$ and digested with various restriction endonucleases. Products of digestion were resolved on $1.0 \%$ agarose, transferred to nitrocellulose, and hybridized with SV40 probe. Lanes: 1 , undigested; $2, B g l$ II; 3, EcoRI; 4, Bgl I; 5, Hpa II; 6, BamHI; 7, Pvu II; 8, Hpa I; 9, Pst I. 
A21 soon after transformation by the SV40 gene $A$ mutant tsA58. Cells within the A21 population became heterogeneous with respect to the arrangement of viral sequences as a result of a labile interaction of SV40 DNA with the host genome. While reselected subclones of $\mathrm{A} 21$ often acquired new high molecular weight sites of SV40 integration as defined by restriction endonuclease digestion with the no-cut enzyme $B g l$ II, cleavage with enzymes having single or multiple specificity for SV40 DNA demonstrated the relatedness and common clonal origin of the subclones.

In addition to integrated sequences, A2l cells also contain distinct normal or defective free viral DNA molecules; our results are indicative of an ongoing $\mathrm{T}$ (tumor) antigen-dependent process being responsible for the maintenance of the free viral DNA. The presence of free viral molecules may be indicative of a limited replication of autonomous viral sequences persisting in mouse cells early after transformation; because the mouse cell system has been described as completely "nonpermissive" for the replication of autonomous SV40 DNA $(1,2)$, continued limited replication of viral plasmids in A21 cells would be contrary to this assumption. Nonetheless, Daya-Grosjean and Monier (23), using a hot phenol extraction technique, identified free viral forms in several SV40-transformed lines, including murine lines, although the origin of those molecules was not identified. In addition, free viral DNA was found in osteosarcomas and insulinomas produced by BK virus in the "nonpermissive" hamster system (24). Our results have demonstrated not only the presence but also the dependence of autonomous SV40 DNA on the viral $A$ gene and thus have ruled out the possibility that these forms were simply nonreplicating input viral DNA.

Free SV40 DNA could, alternatively, be generated by an excision of viral monomers from large tandem integration structures, as seen in semipermissive rat cells transformed by polyoma virus $(19,22,25)$. Such a mechanism would reduce the size of the integration site, but the flanking virus-host junctions would be maintained. At this stage we are unable to distinguish between a random distribution of free viral DNA among all cells and the presence of only a few cells producing large amounts of free viral DNA, as found in polyoma-rat transformants (22).

The genetic instability of the original A21 clone leads to the emergence of a heterogeneous subpopulation, from which subclones can be selected that possess individual, but related, integration sites. The experimental data allow us to postulate three mechanisms to explain the altered integration sites, all of which may be active within the evolving A21 cell population: (i) the free viral DNA molecules may be acting as integrative intermediates, thereby creating new sites of SV40 integration; (ii) internal duplication of viral sequences within a tandem integration site could result in the generation of larger inserts; (iii) an amplification and translocation of integration sites may generate additional viral insertions. The distinct relatedness of the integration sites suggests that amplification could be mediated by an unequal crossing-over.mechanism. A similar mechanism has been well characterized in Saccharomyces cerevisiae, in which unequal crossing-over results in the duplication of rRNA genes (26). The frequency of such events would be greatly enhanced if SV40 were integrated into reiterated host sequences.

If the changes in organization of the integrated SV40 sequences early after transformation can be related to changes in the biological expression of the transformed phenotype, then the viral DNA instability that results in the generation of diverse SV40 integration patterns could represent one of the underlying mechanisms by which transformed populations evolve in a multistep fashion toward a fully tumorigenic phenotype (27, 28).

We thank Rebecca Borie and Jayne Maritato for excellent technical assistance and Marlene Chavis for editing and typing the manuscript. This work was supported by Grant CA 16239 from the National Institutes of Health.

1. Martin, M. A. \& Khoury, G. (1976) Curr. Top. Microbiol. Immunol. 73, 35-65.

2. Kelly, T. \& Nathans, D. (1977) Adv. Virus Res. 21, 85-173.

3. Sambrook, J., Westphal, H., Srinivasan, P. R. \& Dulbecco, R. (1968) Proc. Natl. Acad. Sci. USA 60, 1288-1295.

4. Botchan, M., Ozanne, B., Sugden, B., Sharp, P. A. \& Sambrook, S. (1974) Proc. Natl. Acad. Sci. USA 7.1, 4183-4186.

5. Abrahams, P. S., Mulder, C., Van der Voorde, A., Warnaar, S. O. \& Van der Eb, A. S. (1975) J. Virol. 16, 818-823.

6. Botchan, M., Topp, W. \& Sambrook, J. (1976) Cell 9, 269-287.

7. Ketner, G. \& Kelly, T. J. (1976) Proc. Natl. Acad. Sci. USA 73, 1102-1105.

8. Prives, C., Gilboa, E., Revel, M. \& Winocour, E. (1977) Proc. Natl. Acad. Sci. USA 74, 457-461.

9. Crawford, L. V., Cole, C. N., Smith, A. E., Paucha, E., Tegtmeyer, P., Rundell, K. \& Berg, P. (1978) Proc. Natl. Acad. Sci. USA $75,117-121$

10. Fluck, M. M. \& Benjamin, T. (1980) Virology 96, 205-228.

11. Martin, R. G., Setlow, V., Edwards, C. A. F. \& Vembu, D. (1979) Cell 17, 635-643.

12. Frisque, R. S., Rifkin, D. \& Topp, W. (1980) Cold Spring Harbor Symp. Quant. Biol. 44, 325-332.

13. Graessman, A., Graessman, M., Tjian, R. \& Topp, W. (1980) J. Virol. 33, 1182-1191.

14. Campo, M. S., Cameron, I. R. \& Rogers, M. E. (1978) Cell 15, 1411-1426.

15. Steinberg, B., Pollack, R., Topp, W. \& Botchan, M. (1978) Cell $13,19-32$.

16. Hiscott, J. B., Murphy, D. \& Defendi, V. (1980) Cell 22, 535-543.

17. Hiscott, J. B. \& Defendi, V. (1980) Cold Spring Harbor Symp. Quant. Biol. 44, 343-352.

18. Tegtmeyer, P. \& Ozer, H. L. (1971) J. Virol. 8, 516-524.

19. Basilico, C., Gattoni, S., Zouzias, D. \& Della Valle, G. (1979) Cell 17, 645-659.

20. Sharp, P. A., Sugden, B. \& Sambrook, J. (1973) Biochemistry 12, 3055-3063.

21. Southern, E. M. (1975) J. Mol. Biol. 98, 503-517.

22. Zouzias, D., Prasad, I. \& Basilico, C. (1977) J.Virol 24, 142-160.

23. Daya-Grosjean, L. \& Monier, R. (1978) J. Virol. 27, 307-312.

24. Chenciner, N., Meneguzzi, G., Corellini, A., Grossi, M. P., Grassi, P., Barbanti-Brodano, G. \& Milanesi, G. (1980) Proc. Natl Acad. Sci. USA 77, 975-979.

25. Gattoni, S., Colantuoni, V. \& Basilico, C. (1980) J. Virol. 34, 615-626.

26. Szostak, S. W. \& Wu, R. (1980) Nature. (London) 284, 426-430.

27. Dulbecco, R. \& Vogt, M. (1960) Proc. Natl. Acad. Sci. USA 46, 1617-1623.

28. Defendi, V. \& Lehman, J. M. (1965) J. Cell. Comp. Physiol. 66, 351-410. 